at $5 \mathrm{Mc} . / \mathrm{s}$. (nominal frequency) which can be varied continuously to sweep over the resonance line. A small portion of the energy being supplied to the atomic-beam apparatus is taken off by means of a directional coupler and fed to a balanced microwave mixer. This mixer is also fed with the 90,000th harmonic of one of the reference quartz-crystal oscillators $^{6}$ at $100 \mathrm{kc} . / \mathrm{s}$. The resulting beat note is at $192.6 \mathrm{Mc} / \mathrm{s}$. A second beat is obtained between the first beat signal and the 2,000th harmonic of the reference oseillator, thus giving a signal at $7 \cdot 4 \mathrm{Mc} / \mathrm{s}$. This frequency is then measured by means of an electronic frequency counter. Fig. 2 shows a block diagram of the frequency-measuring chain described above. Great care has to be taken in keeping down the level of noise because of the high order of frequency multiplication involved. It is possible to make measurements of frequency to an accuracy of $\pm 1 \mathrm{c} / \mathrm{s}$. or $\pm 1: 10^{10}$ within 10 sec., which is nearly the limiting accuracy set by the quartz-crystal oscillators.

The source of cæsium atoms is an oven containing a mixture of cæsium chloride and sodium metal and heated to $200^{\circ} \mathrm{C}$. The full width (at half intensity) of the resonance transition is measured to be $230 \mathrm{c} . / \mathrm{s}$., which is the expected value under the experimental conditions of the beam temperature and the length of the transition region. The frequency of the resonance transition is determined by measuring the frequency at points of equal amplitude on both sides of the resonance. A magnetic field or $C$ field of $0.04-0.07$ oersted is used such that a correction of the frequency of $1-2 \mathrm{c} / \mathrm{s}$. is needed to obtain the

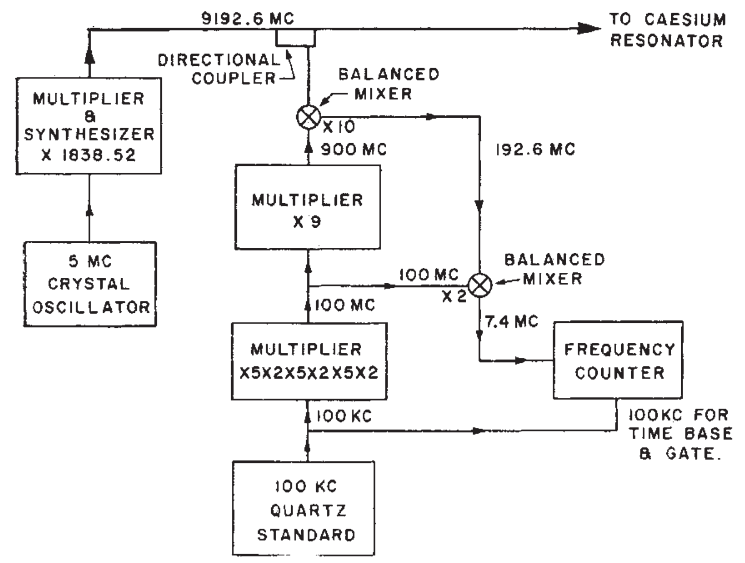

Fig. 2. Block diagram of the frequency-measuring chain used in crsium-133 frequency resonator standard

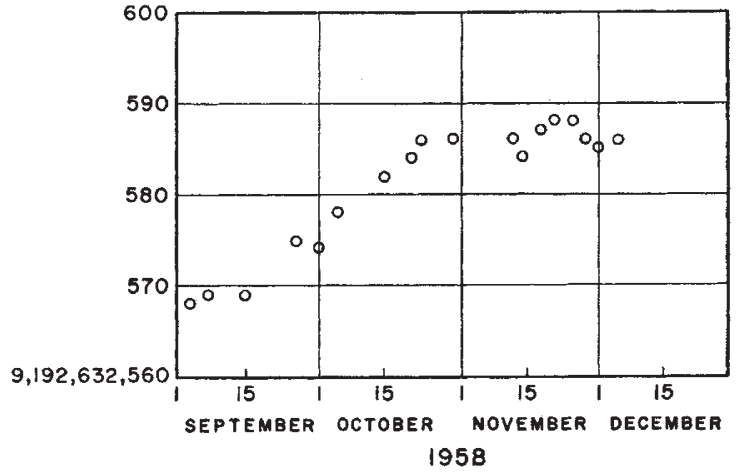

Fig. 3. Ratio of the frequency of the crsium-133 resonance transition and reference oscillator $A P$. The ordinate expresses assumption that the reference oscillator has the exact nominal frequency

frequency of the zero-field transition. This correction is determined and applied for each observation. The sensitivity of the measurements is about $\pm 1 \mathrm{c} / \mathrm{s}$. or $1: 10^{10}$ and the sum of the systematic errors is less than $10 \pm 10 \mathrm{c} . / \mathrm{s}$.

The ratio of the frequencies of the cæsium-133 $(4,0 \longleftrightarrow 3,0)$ transition and the reference oscillator $A P$ (100 kc. $/ \mathrm{s}$. nominal frequency) is shown in Fig. 3 for a period of three months. It should be emphasized that the ordinate in Fig. 3 does not represent the frequency of the cæsium resonator in cycles per second, but is simply a ratio determined in the course of measurement of the frequency of one of the reference quartz-crystal oscillators against the cæsium resonator. The second of Universal Time 2 as tentatively determined for September 1958 by the Dominion Observatory, Ottawa, gives $9192631935 \pm$ $50 \mathrm{c} . / \mathrm{s}$. as the frequency for the cæsium transition $F=4, m_{F}=0 \longleftrightarrow F=3, m_{F}=0$ at zero field. This value is subject to revision as the unit of time is revised. The magnitude of the uncertainty is governed mainly by the accuracy of the determination of the second.

${ }^{1}$ Kalra, S. N., Bailey, R., and Daams, H., Canad. J. Phys., 84, 1442 (1958).

${ }^{2}$ Essen, L., and Parry, J. V. L., Phil. Trans. Roy. Soc., A, 250, 45 (1957)

Essen, L., Parry, J. V. L., Markowitz, W., and Hall, R. G., Nature, 181, 1054 (1958).

${ }^{4}$ Markowitz, W., Hall, R. G., Essen, L., and Parry, J. V. L., Phys. Rev. Letters, 1, 105 (1958).

${ }^{5}$ Ramsey, N. F., Phys. Rev., 78, 695 (1950).

- Kalra, S. N., Pattenson, C. F., and Thomson, M. M., Canad. J. Phys., 37, 10 (1959).

\title{
OBITUARIES
}

\section{Mr. F. R. Petherbridge}

Frederick Robert Petherbridge died on August 15,1958 , at the age of seventy after a long illness. Before his retirement in 1946 he was widely known and respected in agricultural circles for his work in applied entomology. When first appointed as advisory biologist, under the Ministry of Agriculture and Fisheries, he was expected to advise single-handed on pests and diseases of field and fruit crops throughout the Eastern Advisory Province and also to undertake seed testing. Later, after the appointment of Dr. W. A. R. Dillon Weston as mycologist, Pether- bridge devoted his time entirely to pests. Together they were able to win the confidence of East Anglian farmers and to enhance the reputation of the School of Agriculture, Cambridge, both provincially and nationally as a source of advice on pests and diseases.

Robert Petherbridge was born, the son of a fruit dealer, on March 9, 1888, in Allerford, Somerset, and was educated at West Somerset County School and Sidney Sussex College, Cambridge. He obtained first-class honours in the Natural Science Tripos Part $I$ in 1909, and took the diploma in agriculture in 1910. Though lacking inches he was a very good association football player, but it was his keen interest 
in rugby that most of us will remember, and especially his regular attendance at the Oxford-Cambridge match.

After a short period at Rothamsted Experimental Station, where he was contemporary with Sir John Russell and the late Tom Goodey, he returned to the University School of Agriculture, Cambridge, in 1912, as advisory biologist, continuing in that post until 1946. Being a member of the advisory staff, Petherbridge played only a minor part in formal teaching in the School of Agriculture, but his wide experience and his genial influence was exercised in the supervision of students and the training of research workers, many of whom now hold important posts. His approach to research was essentially practical, and many students fresh from academic training had cause to be very grateful to him for a thorough grounding in field-work.

A good deal of Petherbridge's early work was done on fruit in the Histon-Cottenham and Wisbech areas and later in Essex. He was able to identify at a glance all common varieties of fruit, and the advice he gave was always based on sound practical and economic considerations. But though fruit pests claimed much of his time he was also a pioneer in many other aspects of pest control, particularly those of arable Fenland crops. The onset of the Second World War and the vigorous policy of ploughing up grass led to the setting up of a wireworm team which, besides advising farmers, undertook research on factors affecting population-levels.

Petherbridge began an association with the Committee for Sugar Beet Research in 1934 and initiated work on sugar beet pests. In a determined effort to avoid the difficulties from beet eelworm which had plagued the Continental beet sugar industry, he proposed legislation to regulate frequency of eropping in the important Fenland area. This proposal was accepted and formed the basis of the Sugar Beet Eelworm Order, still in force. Another interesting proposal, which was not accepted, was the eradication of the spindle tree, the winter host of the black bean aphid and a scourge to beet seed and root crops.

Petherbridge's dynamic personality always claimed serious attention at the conference table and at meetings of applied biologists everywhere. He fought enthusiastically and successfully for raising the salary and the status of the adviser and particularly that of his assistants and of junior entomologists elsewhere in the service. He abhorred red tape and he was very disappointed when the old advisory service was dissolved and the National Agricultural Advisory Service was formed in 1946 ; all members of the team that he had gathered together left the Service at this juncture and he himself retired early. For some years he maintained his interests in association with Pest Control, Ltd., and continued to serve as consultant entomologist to the Royal Agricultural Society of England-a post he took over from the late Cecil Warburton.

F. G. W. JONES

\section{Dr. F. A. Burchardt}

Dr. F. A. Burchardt, who died on December 21 in Oxford at the early age of fifty-six, was acknowledged to be one of the most perceptive and vigorous economists of his time. His work at the Universities of Kiel and Frankfurt had, nearly thirty years ago, already established his reputation as a theoretician; but his intellectual and personal integrity was enough to ensure his dismissal as soon as the Nazis took power. For two tense years he worked as economic and financial editor of the Frankfurter Zeitunguntil this last foothold became untenable. He arrived in Oxford in 1935 with a small research grant from All Souls College. He now had simultaneously to adapt himself to a new academic climate, to master the difficulties of teaching and lecturing in a strange language, and to build a fresh background for his young family.

Burchardt turned his mind to statistics and applied economics : indeed, he did much to establish empirical economic research in Oxford. He joined the staff of the Institute of Statistics, eventually becoming its director in 1949. He had been elected a Fellow of Magdalen College the year before, and in 1950 was appointed reader in economic and social statistics in the University. During 1952 he went to Stanford University as visiting professor ; in the same year he became a governor of the National Institute for Economic and Social Research ; in 1954 he was elected a member of the International Statistical Institute and a Faculty Follow of Nuffield College; he reported for the European Productivity Agency in 1955, and worked in the Economic Commission for Europe during 1956-57. His help was welcomed in many other fields-among them that of adult education both in Britain and in Germany.

He had an immense capacity for work, and combined his many activities with devoted service to the Institute of Statistics, his College, and the University. An unfeigned interest in other people's views, a startlingly quick perception of what they were trying to say, and a faculty -almost an instinct-for distinguishing truth from mere plausibility made him an outstanding teacher. At the Institute, he inaugurated many pioneering projects in applied economics. Although he provided an unfailing stimulus to his colleagues, never grudging them detailed criticism, he never took credit and always encouraged them to claim, and to achieve, their independence. Those who knew him will always remember his intellectual vitality, his ready humour, and his utter unselfishness.

\section{K. G. J. C. KNowLes}

\section{The Hon. Mrs. Ursula Grant Duff}

The Hon. Ursula Grant Duff, widow of Lieut.-Col. Adrian Grant Duff (killed in action in 1914), died on January 15, a few days before her seventy-fourth birthday, and was buried at High Elms, Farnborough, Kent. Her father was Sir John Lubbock (later Lord Avebury); her maternal grandfather was the pioneer archæologist, General Pitt-Rivers; and at High Elms, where Charles Darwin was a neighbour, she grew up in one of the liveliest centres of intellectual ferment in England.

Many sorrows followed the death of her father in 1913, but she continued the High Elms tradition at her Chelsea home with infectious gaiety and unassuming devotion to the improvement of personal, intergroup and international relations. The leading figures of the biological and social sciences were among her frequent guests, but there were always younger workers and representatives of other disciplines to meet them. Her relations with Nature and its contributors were particularly close.

Her own interests ranged from liberal rationalism and the rights of women to eugenics and constructive forestry; but all were linked in her mind as ways to 